\title{
ESTUDO DE OCORRÊNCIAS PATOLÓGICAS EM PONTES COM A UTILIZAÇÃO DE VEÍCULOS AÉREOS NÃO TRIPULADOS
}

\author{
A. C. ROSENBERG \\ Estudante \\ Universidade Vila Velha - UVV \\ Espírito Santo - ES; Brasil \\ andrecasagranderosenberg@hotmail.com
}

\author{
B. L. SACHT \\ Estudante \\ Universidade Vila Velha - UVV \\ Espírito Santo - ES; Brasil \\ bernardol.sacht@gmail.com
}

\author{
M. C. R. SILVA \\ Estudante \\ Universidade Vila Velha - UVV \\ Espírito Santo - ES; Brasil \\ Mathews.calixto.rs@hotmail.com \\ B. CEOTTO_SOBRINHO \\ Professor \\ Universidade Vila Velha - UVV \\ Espírito Santo - ES; Brasil \\ bruno.sobrinho@uvv.br
}

\section{RESUMO}

Como todas as obras na construção civil, as pontes e viadutos são concebidos para desempenharem suas funções durante um período mínimo de tempo denominado vida útil de projeto (VUP). Entretanto, inúmeros fatores podem interferir para o aumento ou redução deste prazo. Problemas oriundos de erros de projeto ou má execução, assim como a falta de manutenção, dentre outros, são fatores que podem reduzir a vida útil das obras em geral. Para que se possa prolongar a vida útil de uma estrutura e preservar a sua segurança e funcionalidade, faz-se necessária a realização de manutenções regulares e a adoção de medidas corretivas. Desta forma, os serviços de inspeção constituem-se numa ferramenta essencial para a avaliação do estado de conservação das estruturas e o desenvolvimento do sistema de gerenciamento para as mesmas. A inspeção visual normalmente é realizada por meio de registros fotográficos juntamente com o preenchimento de fichas de inspeção contendo a descrição e identificação dos locais das anomalias encontradas. Esse processo, no entanto, requer que a estrutura seja acessível e ofereça condições de segurança para o inspetor. Nesse contexto, o uso de veículos aéreos não tripulados (VANTs) aliado ao processamento de imagens digitais, constitui-se num instrumento de grande auxílio para a inspeção de estruturas tais como as de OAEs, plataformas offshore, fachadas de edifícios e outras, que não permitam acesso direto, ou ofereçam riscos à segurança aos inspetores. O presente trabalho objetiva apresentar o estudo da aplicação do uso de VANT na realização de inspeção da Ponte do Rio Jucú Braço Norte, assim como suas vantagens e limitações, em relação aos métodos tradicionais. Palavras-chave: Drones, Vants, Manifestações Patológicas, Inspeção de Pontes e Viadutos, Obras de Arte Especiais.

\section{ABSTRACT}

Like all civil construction work, bridges and viaducts are designed to perform their functions for a minimum period of time called the useful life (VUP). However, many factors may interfere with the increase or decrease of this period. Problems arising from design errors or bad execution, as well as lack of maintenance, among others, are factors that can reduce the useful life of constructions in general. In order to extend the useful life of a structure and preserve its safety and functionality, regular maintenance and corrective actions are required. Thus, inspection services are an essential tool for assessing the state of conservation of structures and the development of the management system for them. Visual inspection is usually performed using photographic records along with the completion of inspection sheets containing the description and identification of the locations of the anomalies found. This process, however, requires the structure to be accessible and to provide safety conditions for the inspector. In this context, the use of unmanned aerial vehicles (UAVs) combined with digital image processing is a very useful tool for the inspection of structures such as Special Engineering Structures (SESs), offshore platforms, building facades and others that do not allow direct access, or pose safety risks to inspectors. This present work aims to present the study of the application of UAV use in the inspection of the Jucú Braço Norte River Bridge, as well as its advantages and limitations, in relation to the traditional methods.

Keywords: Drones, Vants, Pathological Manifestations, Inspection of Bridges and Viaducts, Special Works of Art. 


\section{INTRODUÇÃO}

As Obras de Arte Especiais (OAEs) são construções que, devido às suas características técnicas, requerem projetos com abordagens mais específicas, tais como pontes, viadutos, passarelas e túneis. Assim como qualquer edificação, toda obra de arte especial (OAE) está sujeita aos desgastes naturais decorrentes das condições ambientais e das condições de uso a que estão submetidas. Além disso, devido às suas peculiaridades, estas construções também estão sujeitas a colisões e incêndios, que também podem afetar a sua integridade. Devido a isso, os serviços de inspeção e manutenção constituem-se em ferramentas indispensáveis para a promoção da durabilidade e o prolongamento da vida útil dessas estruturas.

No Brasil, os serviços de inspeção em OAEs são realizados de acordo com as recomendações contidas na NBR 9452:2019 ou na norma do Departamento Nacional de Infraestrutura e Transportes (DNIT), conhecida como DNIT 010:2004 - PRO. As inspeções constituem-se em um conjunto de atividades técnicas especializadas, que se destinam à coleta de dados de uma obra, em determinado instante, assim como a coleta de informações relativas aos seus projetos e, quando possível, informações relativas ao seu período de construção. A coleta de dados possibilita a avaliação do estado de conservação da obra, além de permitir a elaboração de relatórios contendo recomendações sobre possíveis obras de manutenção, tais como pequenos reparos, recuperação, reforço ou mesmo reabilitação.

O DNIT possui um sistema próprio para realizar o gerenciamento e monitoramento das OAEs existentes nas rodovias federais brasileiras. Trata-se do Sistema de Gerenciamento de Obras de Arte Especiais (SGO) que, além do cadastramento, é responsável pela avaliação e acompanhamento de 5114 estruturas de OAEs localizadas em rodovias federais (DNIT- DPP, 2016).

No presente trabalho é apresentado o resultado da avalição, baseada em uma inspeção rotineira, realizada na Ponte sobre o Rio Jucu Braço Norte, de acordo com a norma DNIT 010/2004 - PRO.

\section{REALIZAÇÃO DAS INSPEÇÕES}

\subsection{Procedimentos gerais}

De acordo com a Norma DNIT 010/2004 - PRO (DNIT, 2004), a realização da inspeção de uma ponte deve ser feita de maneira sistemática e organizada, visando garantir que todos os seus elementos estruturais sejam inspecionados. Neste sentido, o preenchimento de fichas de inspeção apropriadas, são fundamentais para este trabalho.

Na realização dessas atividades, o registro fotográfico constitui-se num recurso de grande importância, sendo que, em alguns casos, é indispensável o uso de ferramentas para desobstruir a visão das ocorrências patológicas a serem inspecionadas. Quando necessário, deve-se efetuar a limpeza de determinadas áreas da ponte, para verificar se há trincas, corrosões ou outros defeitos encobertos.

O documento fotográfico para registro da inspeção deve ser o mais abrangente possível. Porém deve possuir um suficiente de fotos, onde devem estar registradas a vista superior, vista inferior, vistas laterais, detalhes de apoios, as articulações, as juntas e etc.

As anomalias que eventualmente atinjam os elementos estruturais devem ser minuciosamente examinadas e registradas para que sejam diagnosticadas as suas causas. Além disso, sempre que possível, a ponte deve ser observada durante a passagem de cargas pesadas, a fim de verificar se estão ocorrendo vibrações ou deformações excessivas.

\subsubsection{Métodos de acesso}

O Manual de Inspeções de Pontes Rodoviárias do DNIT define as inspeções rotineiras como atividades de natureza visual, e que devem ser "efetuadas a partir do estrado, do terreno, do nível d'água ou de plataformas e caminhos permanentes, se existentes" (Publicação IPR - 709, 2004, p. 19); e, no caso de equipamentos especiais, estes só devem ser utilizados quando forem o único meio para inspecionar os trechos necessários. Dessa forma, quando as áreas a serem inspecionadas estiverem em locais de difícil acesso, o inspetor pode alcançá-las por meio de veículos ou equipamentos especiais. 
O uso desses equipamentos proporciona acesso seguro às áreas de inspeção, mas, em contrapartida, esse tipo de veículo demanda um alto custo de locação. Atualmente, as empresas especializadas disponibilizam diversas opções de equipamentos especiais para a realização de serviços em locais de difícil acesso. As gaiolas, lanças telescópicas e Barins são algumas opções de equipamentos que podem ser utilizados para o acesso à parte inferior das pontes inspecionadas (Figuras 1 e 2 ).

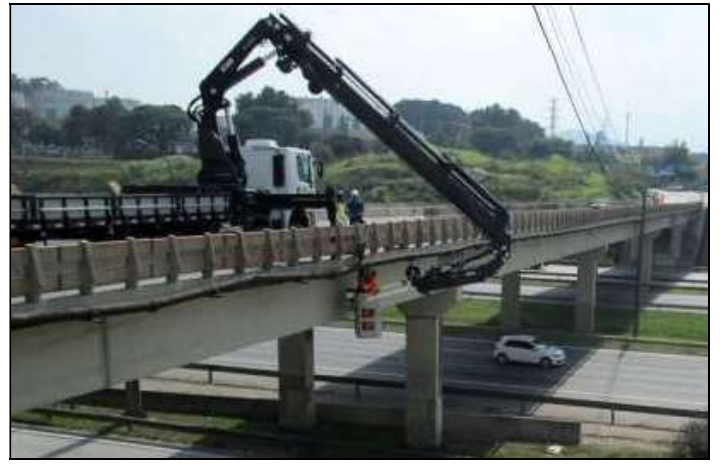

Figura 1: Movimentação operacional com o cesto aéreo Fonte: CUNZOLO (2019)

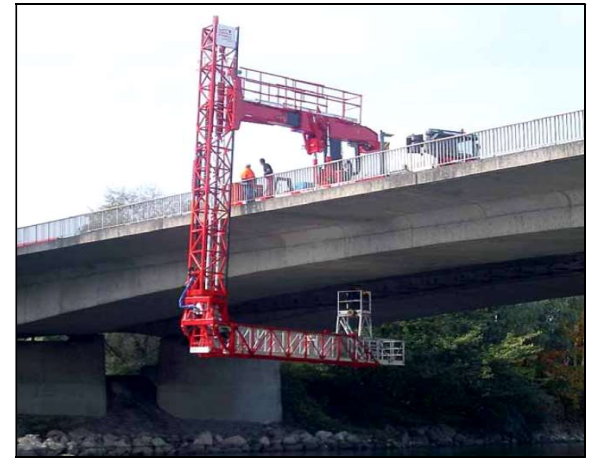

Figura 2: Plataforma Barin para Inspeção de Pontes Fonte: CUNZOLO (2019)

\subsubsection{Uso de Drones}

Para realização do registro fotográfico nos locais de difícil acesso em OAEs, o uso de drones, além das vantagens práticas e econômicas, também agiliza as diligências de campo, mesmo em locais que podem ser acessados diretamente, ou por embarcações.

O drone é controlado remotamente por um profissional altamente capacitado, e que, com uma câmera acoplada, sobrevoa a obra inspecionada realizando o registro fotográfico de toda a estrutura, e obtendo detalhes de pontos específicos ou de difícil acesso.

A utilização desses aparelhos economiza tempo nas atividades de campo, pois, para a sua operação, basta o profissional ligar o equipamento para utilizá-lo sem qualquer preparação prévia (Figuras 3, 4 e 5).

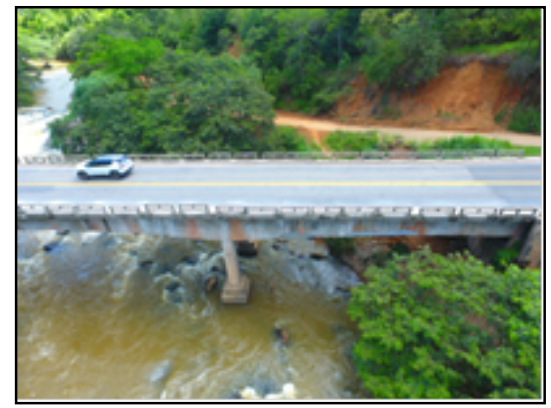

Figura 3: Levantamento aéreo com o drone fazendo imagens panorâmicas Fonte: $\mathrm{O}$ autor

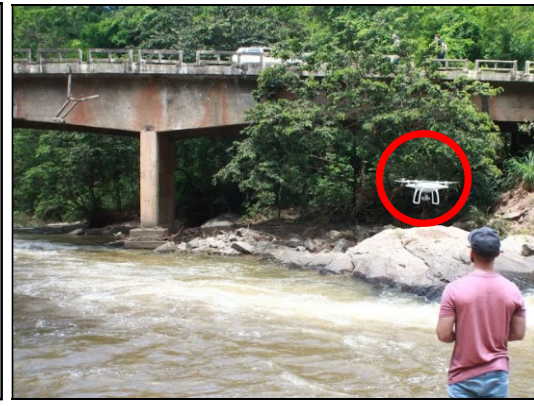

Figura 4: Início da operação de registro fotográfico

Fonte: $\mathrm{O}$ autor

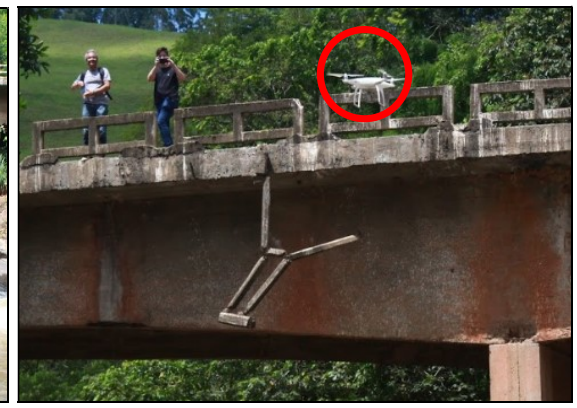

Figura 5: Registro fotográfico com o uso de uma câmera de alta resolução Fonte: $\mathrm{O}$ autor

Hoje em dia, o uso de drones tornou-se um recurso utilizado com grande eficiência na realização das atividades de inspeção em OAEs. Esses veículos possibilitam a otimização dessas atividades, fornecendo fotos e vídeos detalhados dos problemas e anomalias estruturais encontradas. Esse recurso contribui de maneira significativa para a melhoria da qualidade e eficiência nas tarefas de campo, contribuindo para uma maior agilidade nas tomadas de decisão e nos resultados do trabalho.

Devido aos contínuos avanços tecnológicos, os drones estão se tornando ferramentas cada vez mais utilizadas nos serviços de inspeção visual, entretanto, "mesmo com o uso dessa tecnologia não é dispensável o acompanhamento de profissionais habilitados para realização dos trabalhos de vistoria” (ARAÚJO, 2014, p. 62).

Anais do Congresso Brasileiro de Patologia das Construções - CBPAT 2020 


\section{ESTUDO DE CASO}

\subsection{Escolha da ponte de estudo}

A ponte escolhida para a realização do presente estudo de caso denomina-se Ponte sobre o Rio Jucu Braço Norte, e localiza-se na rodovia BR-262/ES - Km 29,1, situando-se na divisa do município de Viana-ES e Domingos Martins-ES (figuras 6 e 7). Esta ponte foi cadastrada no SGO do DNIT no ano de 2019, tendo recebido nota técnica avaliativa igual a 1 , sendo portanto, classificada como crítica.

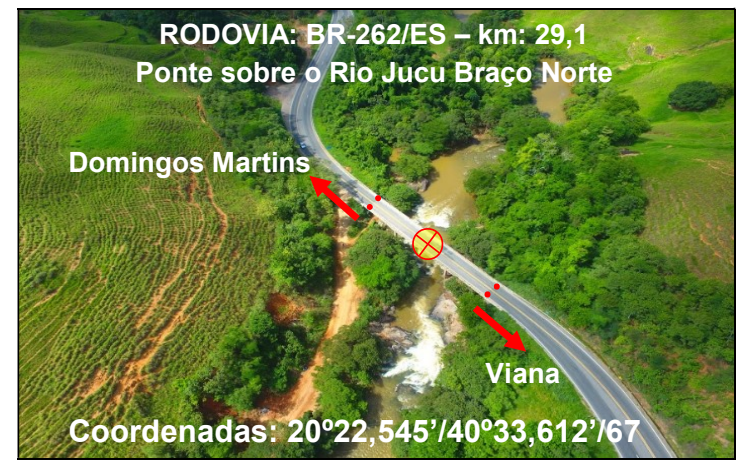

Figura 6: Localização geográfica da ponte Fonte: $\mathrm{O}$ autor

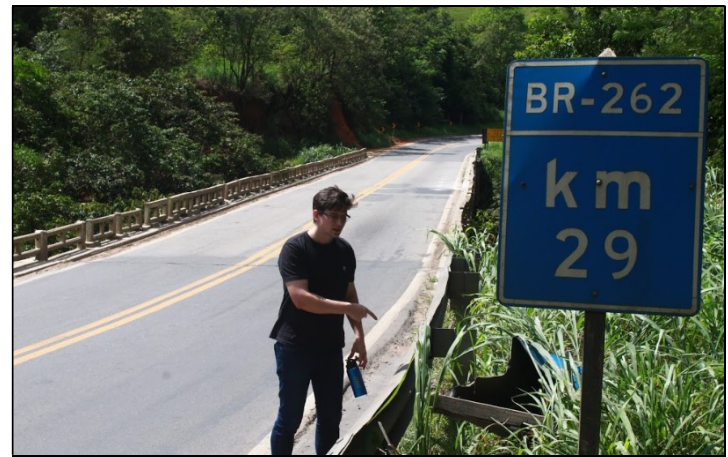

Figura 7: Placa junto ao encontro E2, na divisa do município de Viana-ES - Fonte: $\mathrm{O}$ autor

Foi concluída no ano de 1959, tendo sido executada em concreto armado moldado no local e possuindo encontros nas duas extremidades. Sua estrutura possui dois balanços medindo 6,20 metros cada; um vão central com 27,25 metros, e dois vãos laterais com 18,70 metros cada, totalizando 77,00 metros de comprimento. A seção transversal possui 8,70 metros de largura com o tabuleiro composto por uma estrutura independente em laje maciça executada de concreto armado. A Mesoestrutura constitui-se de dois pórticos de concreto armado, apoiados em dois pilares (figuras 8 e 9).

As informações sobre a ponte foram obtidas no sistema de gerenciamento de obras de arte do DNIT, através de um portal online, onde foi possível pesquisar a ponte em questão. Sua última inspeção realizou-se no início do ano de 2019.

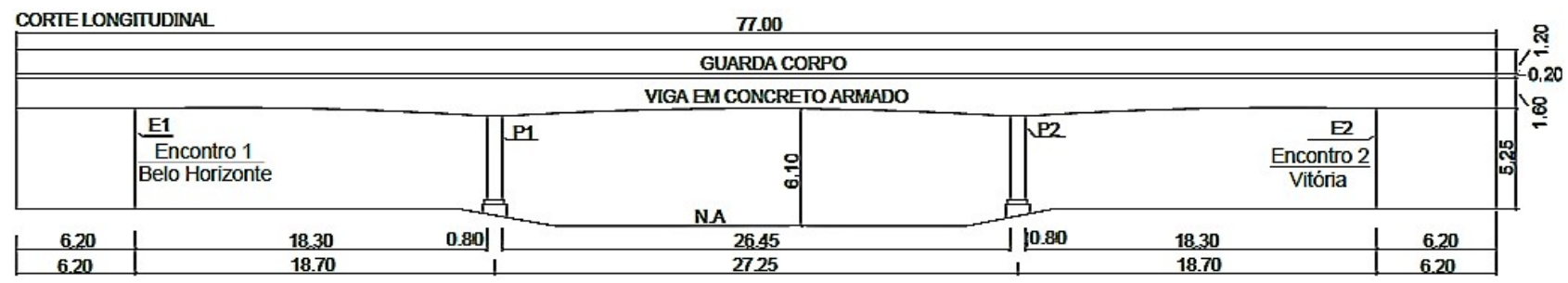

Figura 8: Corte Longitudinal - medidas em metros [m]

Fonte: DNIT - Ponte sobre o Rio Jucu Braço Norte (adaptado pelo autor)

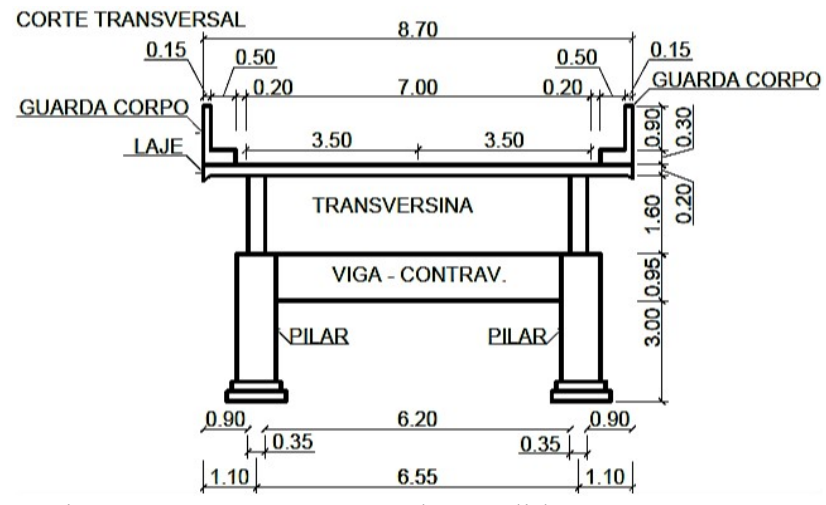

Figura 9: Corte Transversal - medidas em metros [m]

Fonte: DNIT - Ponte sobre o Rio Jucu Braço Norte (adaptado pelo autor)

Anais do Congresso Brasileiro de Patologia das Construções - CBPAT 2020 


\subsection{Realização da inspeção rotineira}

A inspeção foi realizada no dia 14 de dezembro de 2019, sendo observados de forma visual e tátil os elementos da estrutura, elementos de apoio, guarda-corpos, sistema de drenagem, pavimentação e juntas de dilatação. A inspeção também teve como finalidade verificar a evolução das anomalias anteriormente detectadas e o possível surgimento de novas ocorrências. O estudo foi realizado de acordo com as diretrizes recomendadas pela norma de inspeção do DNIT 010/2004 - PRO, e os resultados da inspeção foram registrados na ficha de inspeção rotineira contida no anexo B dessa norma, pois esta é a norma utilizada por este órgão para a gestão de suas OAEs.

A seguir, são exibidas as anomalias observadas nos elementos da estrutura, acompanhadas de registros fotográficos.

\subsubsection{Laje}

Foi identificada grande incidência de eflorescência na laje da estrutura e a presença de estalactites e fissuras (figura 10). Também foi detectado o desplacamento acentuado do concreto na face inferior das lajes do tabuleiro, com a exposição de armaduras em adiantado estado de corrosão (figura 11).

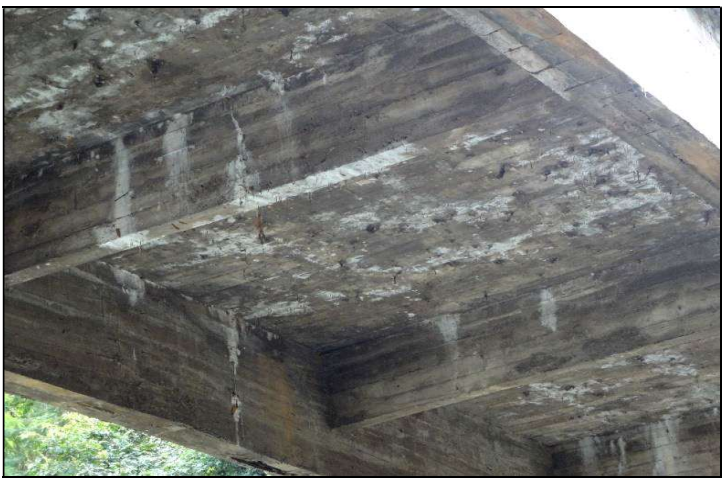

Figura 10: Ocorrência de eflorescências, estalactites e fissuras - Fonte: $\mathrm{O}$ autor

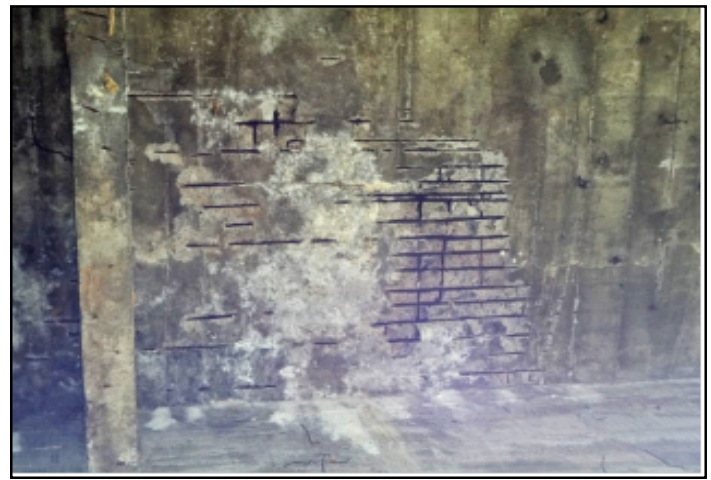

Figura 11: Laje com desplacamento acentuado do concreto e corrosão de armadura - Fonte: $\mathrm{O}$ autor

\subsubsection{Vigamento}

\subsubsection{Longarinas}

As duas longarinas apresentam eflorescências, desagregação e armaduras expostas. Em diversos pontos observa-se a presença de manchas escuras provocadas pelo escorrimento de água de chuva causando a corrosão das armaduras e o desplacamento do concreto (figuras 12 e 13).

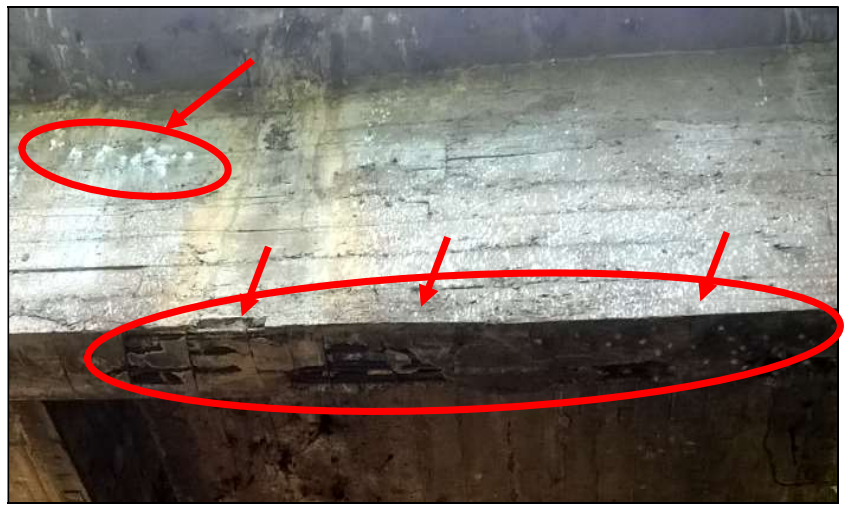

Figura 12: Longarina apresentando eflorescências, desagregação e armaduras corroídas Fonte: $\mathrm{O}$ autor

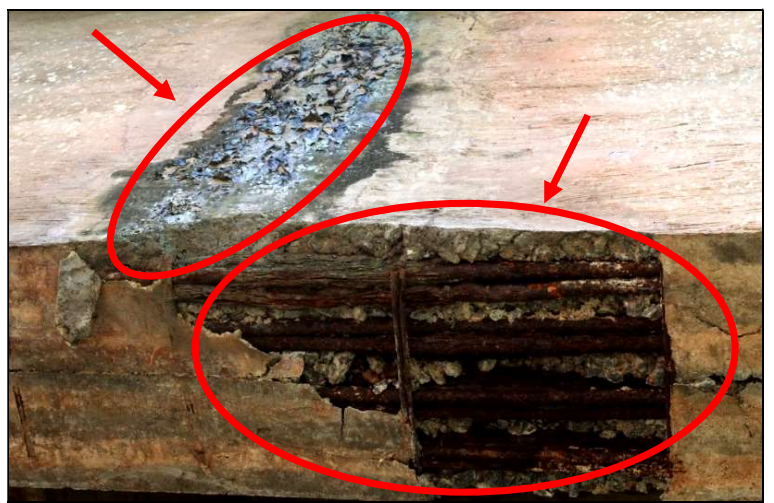

Figura 13: Longarinas com manchas escuras de umidade e armaduras expostas com corrosão acentuada Fonte: $\mathrm{O}$ autor 
Nas figuras 14 e 15, observa-se a existência de ninhos de concretagem e a ocorrência de desplacamento do cobrimento provocado pela corrosão e expansão das armaduras na face inferior da longarina, junto ao encontro E1(Belo Horizonte).

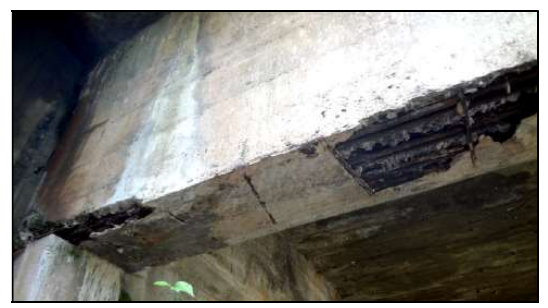

Figura 14: Longarina aprentando ninho de concretagem, desplacamento e corrosão

de armaduras - Fonte: $\mathrm{O}$ autor

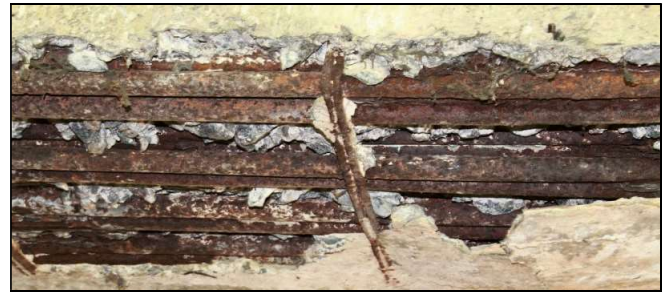

Figura 15: Detalhe do ninho de concretagem Fonte: $\mathrm{O}$ autor

Observou-se, em diversos pontos ao longo das longarinas, trechos com cobrimento insuficiente, onde os estribos estão expostos e sofrendo processo de corrosão (figura 16). Na figura 17 pode-se observar o crescimento de vegetação na face inferior da laje do passeio, eflorescências e, na face inferior da longarina, a corrosão das armaduras estimulada pela água que escorre devido à deficiência do sistema de drenagem.

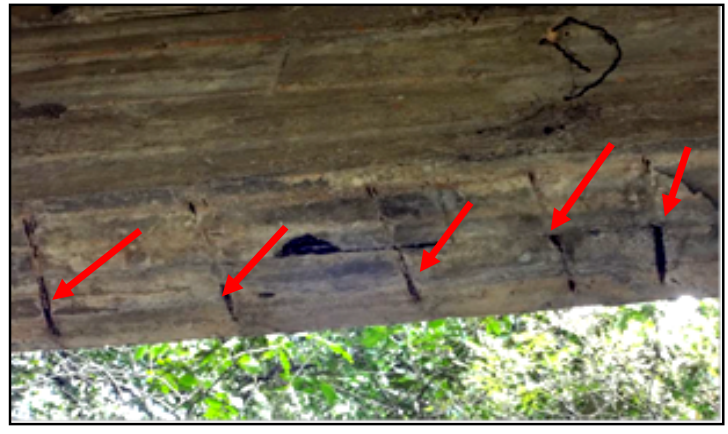

Figura 16: Cobrimento insuficiente e estribos sofrendo processo de corrosão - Fonte: O autor

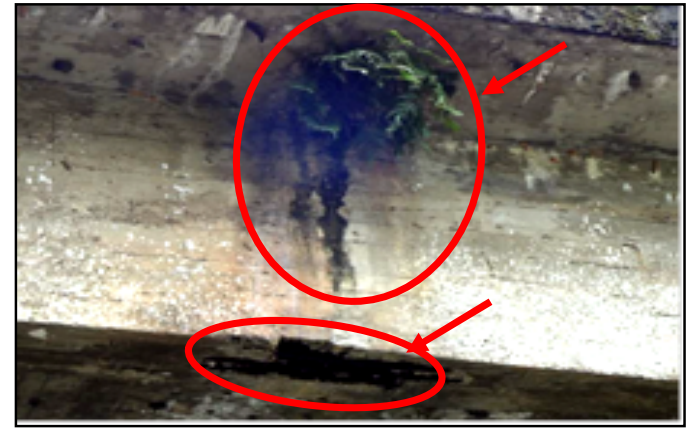

Figura 17: Crescimento de vegetação, eflorescências e corrosão de armaduras - Fonte: $\mathrm{O}$ autor

Também foram observados pequenos reparos realizados em alguns pontos ao longo das longarinas, porém, perante à extensão, gravidade e complexidade de diversos outros problemas e anomalias, tais feitos tornam-se de pouca vaia. Nas figuras 18 e 19 são mostrados dois desses reparos mencionados.

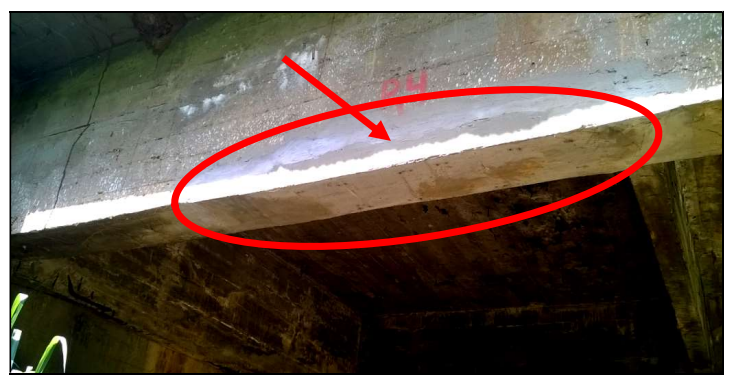

Figura 18: Exemplo de reparo localizado na longarina Fonte: $\mathrm{O}$ autor

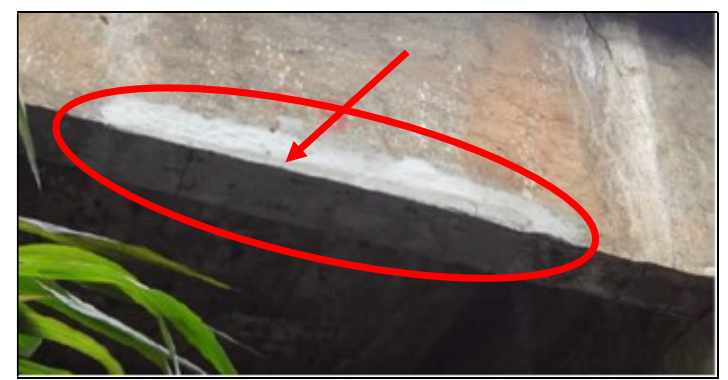

Figura 19: Pequeno reparo localizado na longarina Fonte: $\mathrm{O}$ autor

\subsubsection{Transversinas}

Nas transversinas também foi detectada a presença de manchas de umidade, eflorescências, cobrimento insuficiente, exposição das armaduras e corrosão. Na figura 20 é possível observar que, devido ao cobrimento insuficiente, os estribos estão praticamente expostos ao ambiente, ocasionando a corrosão dos mesmos. Observa-se também que nas faces laterais das longarinas existem vergalhões que foram inadequadamente utilizados para travamento dos gastalhos das formas e que se encontram em processo de corrosão. 
Detectou-se a presença de diversas manchas de eflorescências em todas as longarinas pertencentes a ponte, tais manchas podem ser vistas através da figura 21.

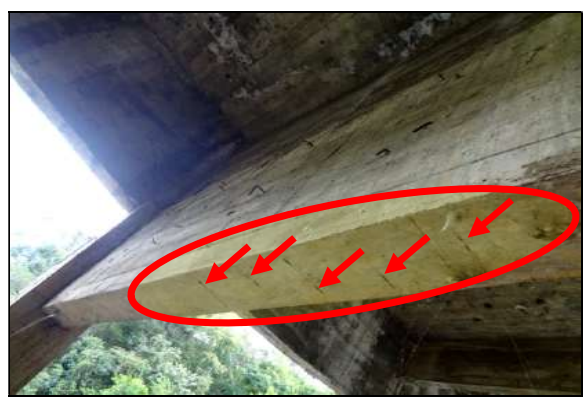

Figura 20: Cobrimento insuficiente na Transversina - Fonte: $\mathrm{O}$ autor

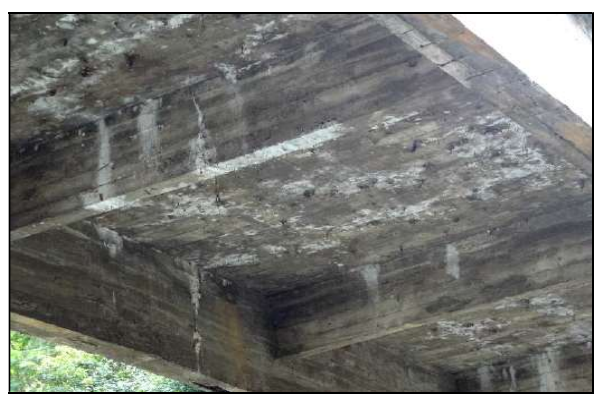

Figura 21: Transversinas com presença de eflorescências - Fonte: O autor

\subsubsection{Mesoestrutura}

\subsubsection{Aparelhos de apoio}

Nas figura 22 e 23 verifica-se que as longarinas encontram-se apoiadas diretamente sobre os pilares, inexistindo aparelhos de apoio. Na figura 23 observa-se que já existe um severo comprometimento da armadura longitudinal da longarina junto ao apoio. Tal fato é de elevada gravidade e coloca em risco a segurança da estrutura dessa ponte, pois, diferentemente de outros tipos de estruturas, as pontes estão submetidas a vibrações e, no caso em questão, tendo sido construída a 60 anos, as solicitações a que ela está submetida atualmente são superiores àquelas a que foi originalmente projetada. Esse diagnóstico é preocupante e indica que essa longarina está sujeita a sofrer uma ruptura frágil, mediante colápso repentino (sem aviso). Identifica-se assim a necessidade de intervenções de manutenção de curto prazo, para que se realize a recuperação necessária.

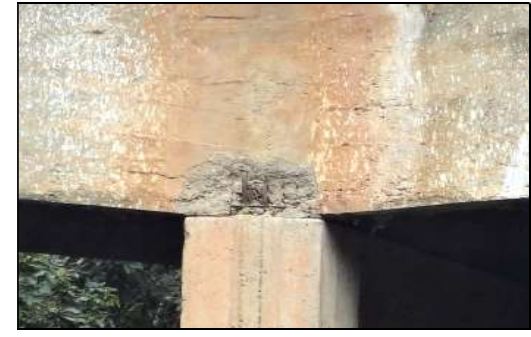

Figura 22: Longarina apoiada diretamente sobre pilar - Fonte: $\mathrm{O}$ autor

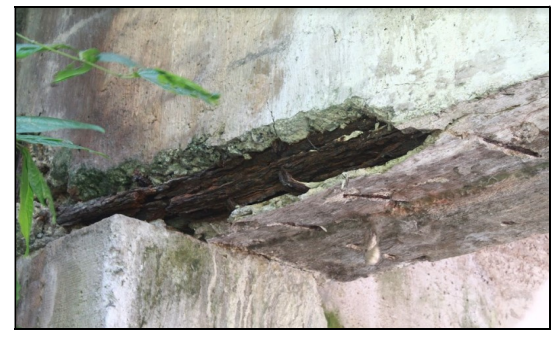

Figura 23: Corrosão da armadura da longarina junto ao apoio - Fonte: $\mathrm{O}$ autor

\subsubsection{Pilares}

Através da inspeção visual, pode-se observar que os pilares encontram-se em melhor estado de conservação em comparação com outros elementos da estrutura, porém, ainda assim não estão livres de problemas. Na base dos pilares centrais, verificou-se a ocorrência de concreto segregado e exposição de armaduras, tais situações podem ser observadas nas figuras 24 a 25 .

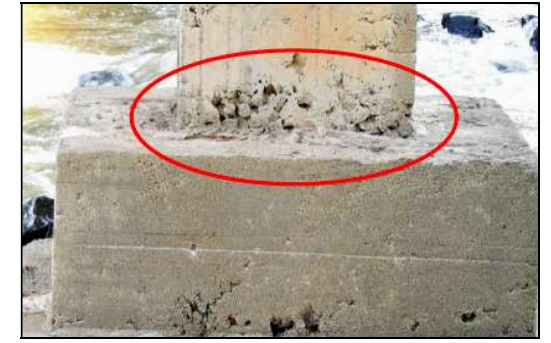

Figura 24: Pilar com concreto segregado Fonte: $\mathrm{O}$ autor

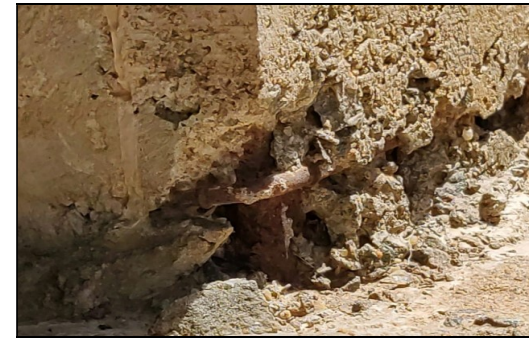

Figura 25: Pilar com armadura exposta - Fonte: $\mathrm{O}$ autor

Anais do Congresso Brasileiro de Patologia das Construções - CBPAT 2020 
Já o pilar do encontro de Domingos Martins apresenta seção transversal rompida e com exposição de armaduras, problema que pode ter sido causado por excesso de carga sobre a estrutura, como pode ser visualisado na figura de 26 .

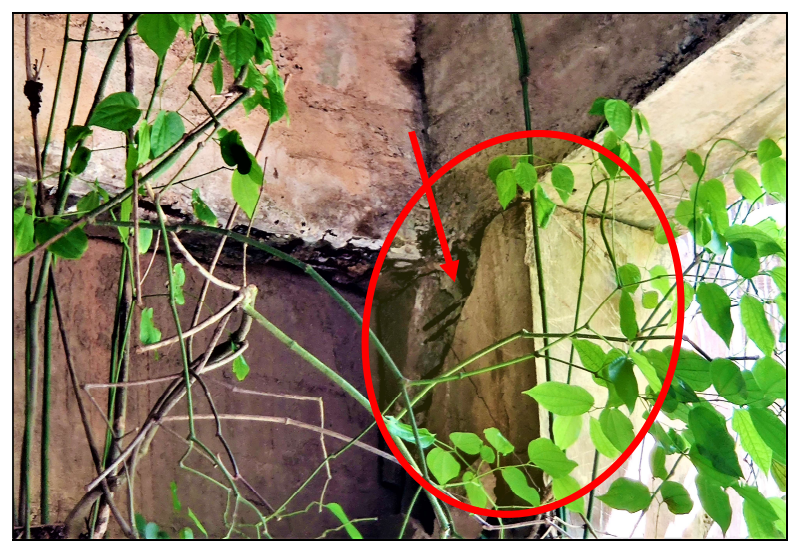

Figura 26: Pilar com seção rompida e armadura exposta - Fonte: $\mathrm{O}$ autor

\subsubsection{Encontros}

Os encontros apresentam sérios problemas de infiltração e corrosão das armaduras. Nos dois encontros detectou-se uma severa corrosão das armaduras, além de eflorescências, trincas e desplacamentos do concreto (figuras 27 e 28).

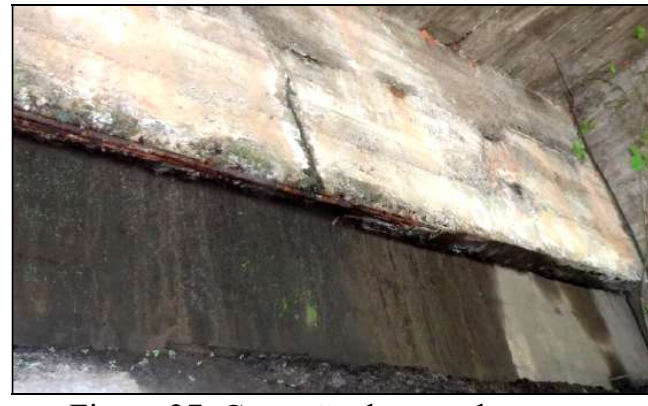

Figura 27: Corrosão de armaduras no encontro E1 - Fonte: $\mathrm{O}$ autor

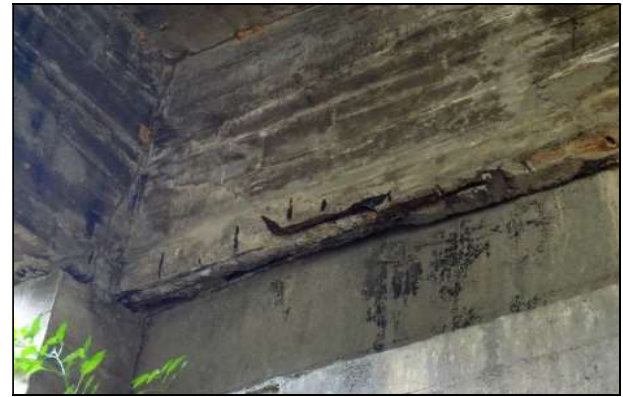

Figura 28: Corrosão de armaduras no encontro E2 - Fonte: $\mathrm{O}$ autor

\subsubsection{Infraestrutura}

\subsubsection{Blocos de fundação}

Verificou-se uma acentuada lixiviação na base dos blocos de fundação, além de sinais de um concreto poroso e mal vibrado, com ocorrência de ninhos de concretagem (figuras 29 a 30).

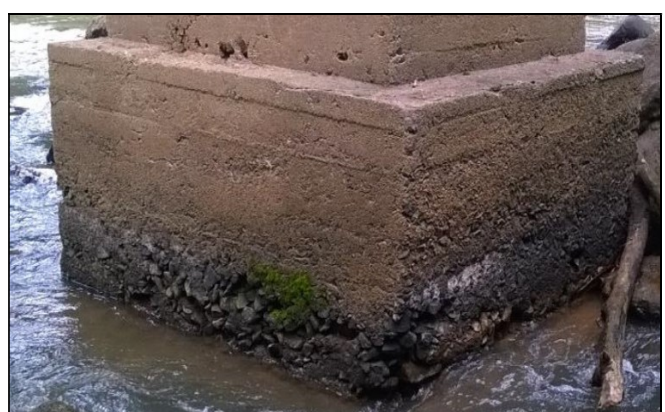

Figura 29: Lixiviação acentuada em bloco de fundação - Fonte: $\mathrm{O}$ autor

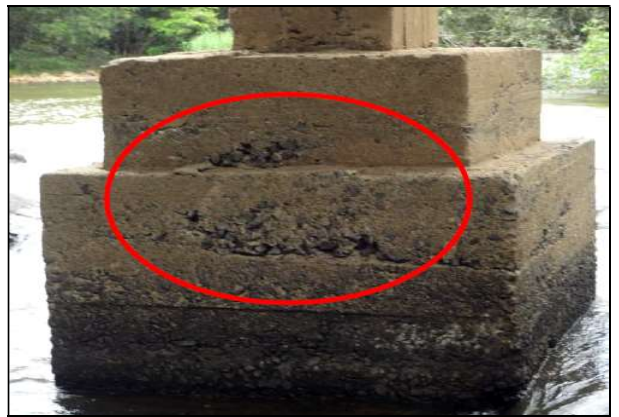

Figura 30: Ninhos de concretagem em bloco de fundação - Fonte: $\mathrm{O}$ autor 


\subsubsection{Pista e Acessos}

\subsubsection{Revestimento do Tabuleiro}

Apesar de apresentar algumas fissuras que facilitam a passagem de água, o restante do pavimento da ponte em estudo encontra-se em um estado aceitável de conservação assim como os encontros entre a ponte e a pista. Tais descrições podem ser vistas nas figuras 31 e 32 .

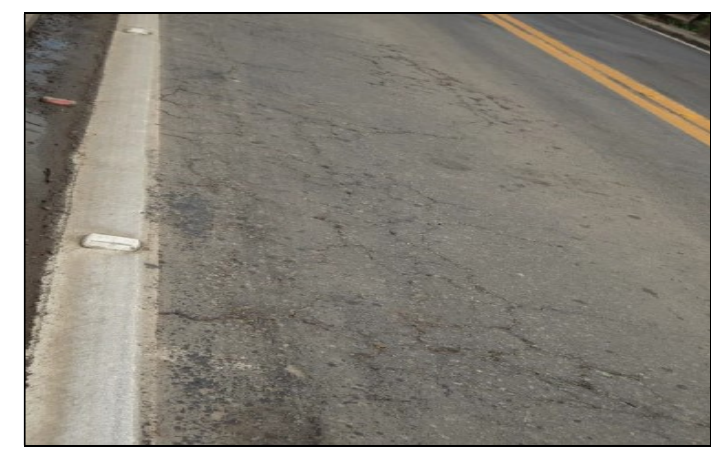

Figura 31: Fissuras no revestimento do tabuleiro da ponte - Fonte: $\mathrm{O}$ autor

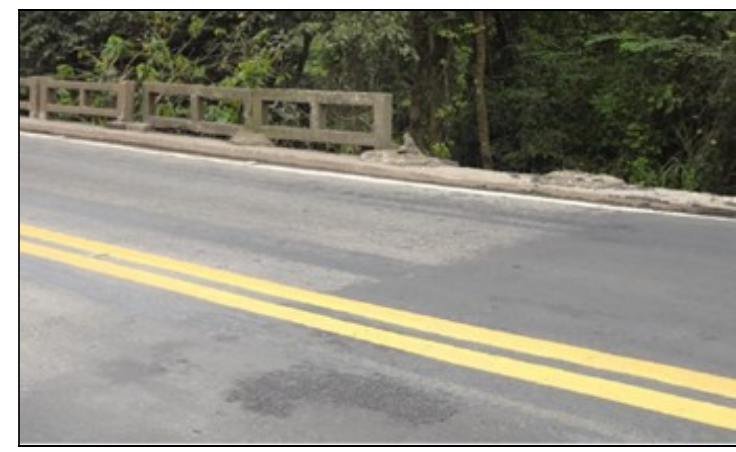

Figura 32: Encontro da pista com a ponte Fonte: $\mathrm{O}$ autor

\subsubsection{Sistema de Drenagem}

Como pode ser visto nas figuras 33, 34 e 35, o sistema de drenagem da pista encontra-se em péssimas condições de funcionamento, pois grande parte deles encontra-se parcialmente entupida e alguns estão completamente obstruídos.

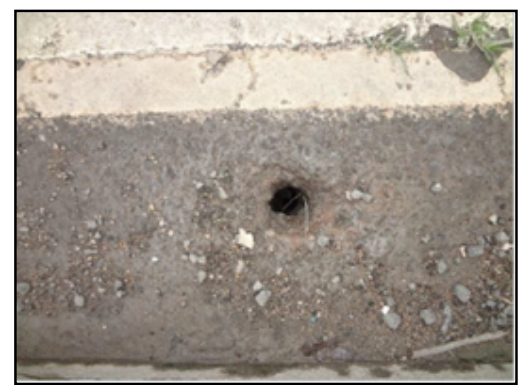

Figura 33: Orifício irregular do dreno da pista - Fonte: $\mathrm{O}$ autor

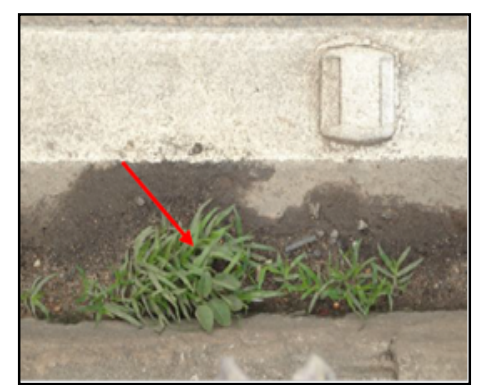

Figura 34: Drenagem entupida por vegetação - Fonte: $\mathrm{O}$ autor

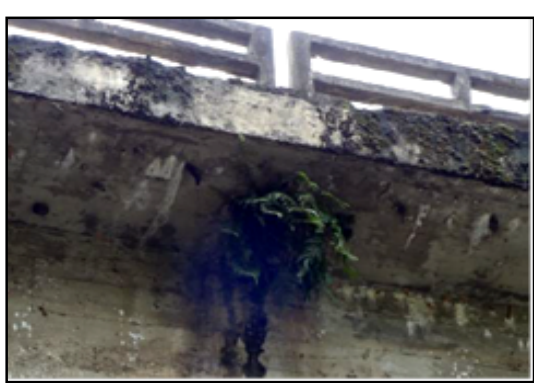

Figura 35: Crescimento de vegetação sob o sistema de drenagem - Fonte:O autor

O sistema de drenagem de canaletas da ponte também se encontra obstruído. Observam-se peças que se desprenderam de veículos e placas caídas obstrutindo o local. Além disso, existe acumulo de vegetação que também provoca o entupimento das mesmas (figuras 36 e 37).

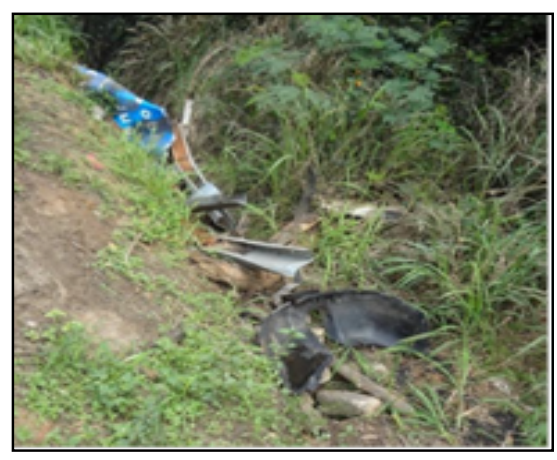

Figura 36: Canaleta de drenagem Obstruída - Fonte: $\mathrm{O}$ autor

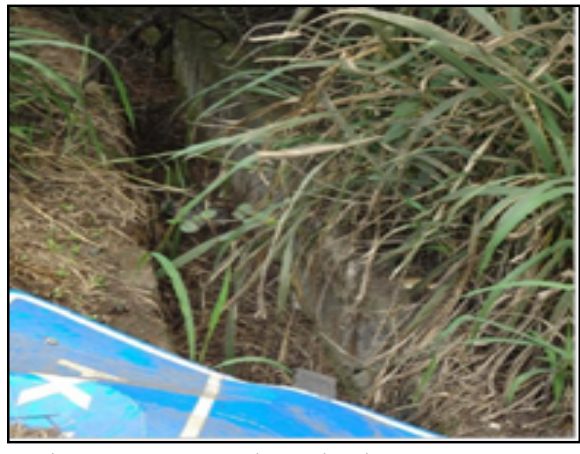

Figura 37: Canaleta de drenagem com acumulo de vegetação - Fonte: $\mathrm{O}$ autor 


\subsubsection{Juntas de dilatação}

Atualmente não existem juntas de dilatação na ponte, entretanto, há indícios de sua possível existência junto ao guarda roda da ponte (figuras 38 e 39). Dessa forma, é possível inferir que as mesmas originalmente tenham existido, mas que tenham sido obstruídas quando o pavimento da pista foi reformado.

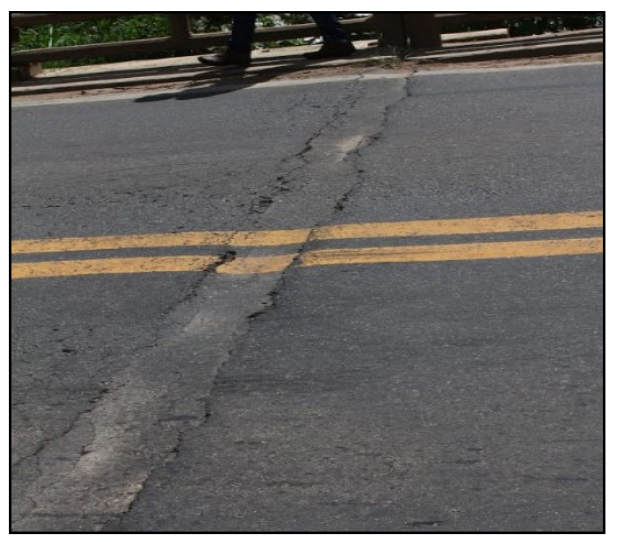

Figura 38: Inexistência de juntas de dilatação na ponte - Fonte: $\mathrm{O}$ autor

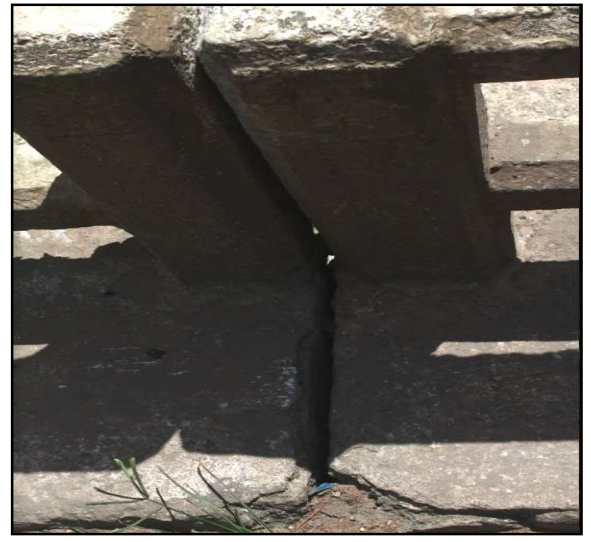

Figura 39: Indício de existência de junta de dilatação - Fonte: O autor

\subsubsection{Guarda-corpo de concreto armado}

Os guarda-corpos da ponte apresentam risco de acidentes aos usuários, pois encontram-se muito deteriorados e em estado crítico de conservação (figuras 40 e 41). Verificou-se também a existência de muitas partes de guarda-corpos caídas às margens da rodovia, conforme pode se ver na figura 42.

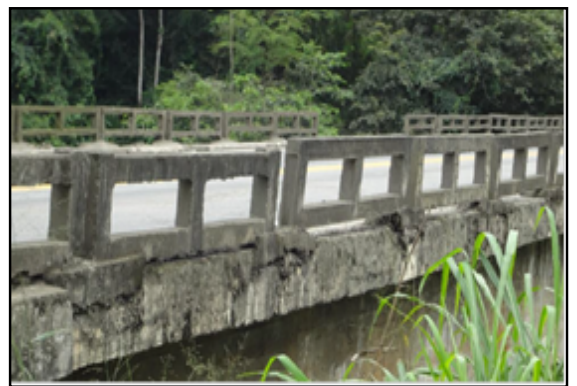

Figura 40: Deterioração dos guarda-corpos - Fonte: O autor

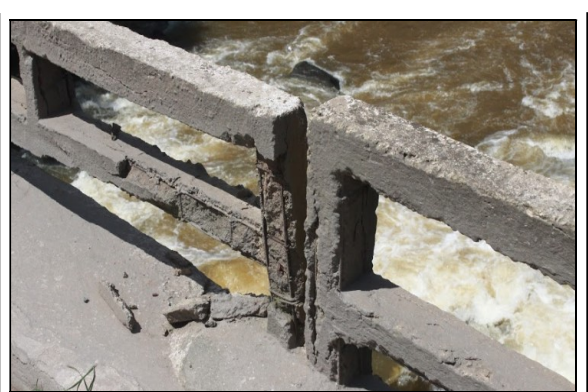

Figura 41: Guarda-corpo em estado crítico - Fonte: $\mathrm{O}$ autor

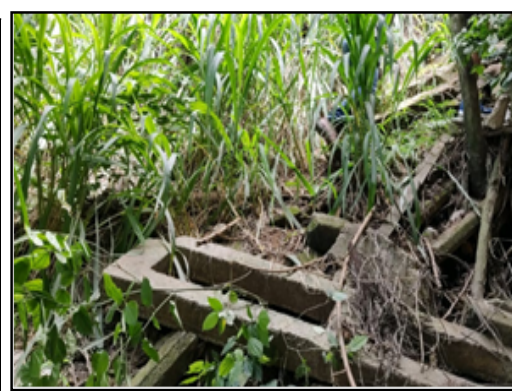

Figura 42: Partes de guarda-corpos caídas - Fonte: $\mathrm{O}$ autor

\section{AVALIAÇÃO E ATRIBUIÇÃO DE NOTAS}

De acordo com os fatos constatados durante a inspeção, foram observados danos provocados pela falta de cobrimento mínima os quais provocaram a oxidação das armaduras e sua exposição consequentemente, e encontrados ao longo de toda a estrutura, um ponto crítico observado foi o desplacamento e exposição da armadura de um dos apois do encontro de Domingos Martins o qual foi criterioso para conclusão da análise, sendo assim, a classificação adotada para esta estrutura através do Anexo B da norma DNIT-10/2004 PRO foi de 1 (um), portanto, considerada como crítica conforme pode ser observado na figura 43. 


\begin{tabular}{|c|c|c|c|c|}
\hline 1. LAJE & & Nota Técnica: & Local & Quanlantidade (Opcional) \\
\hline Buraco (abertura) & $\square$ Existe & $\square$ É Iminente & & \\
\hline Armadura Exposta & $\square$ Muito Oxidada & $\mathbf{X}$ Grande Incidência & Ao longo de toda estrutura & \\
\hline Concreto Desagregado & $\square$ Muita Intensidade & ૫ Grande Incidência & & \\
\hline Fissuras & $\mathbf{X}$ Forte Infiltração & $\square$ Grande Incidência & Nos encontros & \\
\hline Marcas de Infiltraçăo & $\square$ Forte & $\square$ Grande Incidência & & \\
\hline Aspecto de Concreto & $\square$ Má Qualidade & & & \\
\hline Cobrimento & X Ausente / Pouco & & Ao longo de toda estrutura & \\
\hline
\end{tabular}

\begin{tabular}{|c|c|c|c|c|}
\hline \multicolumn{2}{|l|}{ 2. VIGAMENTO PRINCIPAL } & Nota Técnica: & Local & Quanlantidade (Opcional) \\
\hline Fissuras Finas & $\square$ Algumas & $\square$ Grande Incidência & & \\
\hline Trincas (fissuras $w>0,3 \mathrm{~mm}$ ) & $\mathbf{X}$ Algumas & $\square$ Grande Incidência & & \\
\hline Armadura Principal & $\mathbf{X}$ Exposta & $\square$ Muito Oxidada & Nas direções dos drenos & \\
\hline Desagreg. de Concreto & $\square$ Muito Intenso & $\square$ Grande Incidência & & \\
\hline Dente Gerber & $\square$ Quebrado/Desplacado & $\square$ Trincado & & \\
\hline Deformaçăo (Flecha) & $\square$ Exagerada & & & \\
\hline Aspectos do Concreto & $\square$ Má Qualidade & & & \\
\hline Cobrimento & XAusente / Pouco & & Ao longo de toda estrutura & \\
\hline
\end{tabular}

\begin{tabular}{|c|c|c|c|c|}
\hline 3. MESOESTRUTURA & & Nota Técnica: & Local & Quantidade (Opcional) \\
\hline Armadura Exposta & $\mathbf{X}$ Muito Oxidada & $\square$ Grande Incidência & & \\
\hline Concreto Desagregado & $\square$ Muita Intensidade & $\square$ Grande Incidência & & \\
\hline Fissuras & $\mathbf{X}$ Forte Infiltração & $\square$ Grande Incidência & & \\
\hline Aparelho de Apoio & $\mathbf{X}$ Danificado & $\square$ Grande Incidência & & \\
\hline Aspecto do Concreto & $\square$ Má Qualidade & & & \\
\hline Cobrimento & $\square$ Ausente/Pouco & & & \\
\hline Desaprumo & $\square$ Há & & & \\
\hline Deslocabilidade dos Pilares & $\square$ Forte & & & \\
\hline
\end{tabular}

\begin{tabular}{|c|c|c|c|c|}
\hline $\begin{array}{l}\text { 4. INFRAESTRUTURA } \\
\text { Recalque de Fundacăo }\end{array}$ & 口 Há & Nota Técnica: & Local & Quantidade (Opcional) \\
\hline Deslocamento de Fundaçăo & 口 Há & & & \\
\hline Erosão Terreno de Fundação & 口 Há & & & \\
\hline Estacas Desenterradas & 口 Há & & & \\
\hline $\begin{array}{l}\text { 5. PISTA / ACESSO } \\
\text { Irregularidades no Pav. }\end{array}$ & X Muita Intensidade & \begin{tabular}{l|l} 
Nota Técnica: & $\mathbf{2}$ \\
$\square$ Grande Extensão
\end{tabular} & Local & Quantidade (Opcional) \\
\hline Junta de Dilatação & $\square$ Faltando/Inoperante & $\square$ Muito Problemática & & \\
\hline Acessos X Ponte & $\square$ Degrau Acentuado & $\square$ Concordância Problem. & & \\
\hline Acidentes com Veículos & XFreqüente & $\square$ Eventual & & \\
\hline
\end{tabular}

ESQUEMAS

Figura 43: Anexo B (normativo) 


\section{CONCLUSÃO}

O presente estudo teve como objetivo apresentar o uso de drones como instrumento auxiliar para a realização de uma inspeção rotineira na Ponte do Rio Jucú Braço Norte, objetivado verificar as suas vantagens e limitações, com relação aos sistemas tradicionais.

A vantagem na utilização desta tecnologia, é que no trecho central, localizado acima do curso d'água existente, ela permitiu o livre acesso à parte inferior do tabuleiro sem a interrupção do tráfego, o que dispensou a realização de um esquema de apoio com participação de vários profissionais.

Por outro lado, a ponte escolhida localiza-se no vale de uma região montanhosa, onde o relevo propicia a canalização de fortes rajadas de vento, o que apresentou um obstáculo considerável para o controle e estabilização do drone. Também ocorreram interferências magnéticas que também dificultaram a realização dos serviços, exigindo maiores cuidados e maior tempo para a realização das atividades.

Além disso, as atividades foram realizadas sem a interrupção do tráfico da ponte, o que também exigiu maior atenção e perícia do operador da aeronave, pois o deslocamento de ar produzido pelos veículos pesados poderia desestabilizar o aparelho.

Dessa forma, foi possível constatar a grande vantagem do uso do drone na realização do registro fotográfico das ocorrências patológicas em locais de difícil acesso.

No entanto, para a realização de atividades com o drone, é preciso realizar o cadastro da aeronave, junto ao site do SISANT (Sistema de Aeronaves não Tripuladas), em nome de uma pessoa ou empresa no Brasil, que será a responsável legal pela aeronave. Para esse cadastro é necessário informar os dados pessoais ou da pessoa jurídica, quando for o caso, além dos dados da aeronave e escolher um número para identificação do equipamento. O SISANT então, indicará um prefixo de identificação que deverá ser afixado na aeronave. Após isso, o SISANT vai gerar uma certidão de cadastro, de porte obrigatório em todas as operações. Esta solicitação pode demorar até 10 dias, porém geralmente sai em algumas horas ou um dia. Além disso, para a realização do voo, é preciso acessar ao site do SARPAS (Solicitação de Acesso de Aeronaves Remotamente Pilotadas) para realizar o cadastro da aeronave e solicitar autorização para a realização do voo. O retorno a essa solicitação é imediato, e, de posse do número do protocolo recebido, o voo fica prontamente liberado.

Mediante esse trabalho, foi possível constatar que o uso de drones, pode contribuir significativamente para as atividades de Inspeção de OAEs, particularmente nos locais de difícil acesso, que poderiam comprometer o andamento das atividades, descartando em certos casos, o uso de equipamentos especiais e treinamentos para execução dos serviços. Como pôde ser verificado neste estudo, as anomalias existentes na estruturas foram identificadas com facilidade, evitando assim um esforço extra que seria demandado em uma inspeção convencional.

Por fim, como esta ponte foi avaliada como Crítica, é necessário que se realize uma intervenção imediata para a sua recuperação, visto que sua condição estrutural é precária, podendo comprometer e por em risco a vida dos usuários, além de se tornar prejudicial para a população já que a BR-262/ES representa umas das principais rotas para economia do estado, e o desvio necessário para tráfego leve seria aproximadamente $43,1 \mathrm{~km}$, e para tráfego pesado seria de 83,1 km por ser necessário uma via que atenda as condições de carga aceitáveis para este tráfego. 


\section{REFERÊNCIAS}

ARAUJO, C. J. R. V. Soluções inovadoras: vistoriando Obras de Arte Especiais. Revista Notícias da Construção. SindusCon, São Paulo, v. 11, n .138, p. 60-62, 2014.

ASSOCIAÇÃO BRASILEIRA DE NORMAS TÉCNICAS. NBR 9452: Inspeção de Pontes, Viadutos e Passarelas de Concreto - Procedimento. Rio de Janeiro, 2019.

DEPARTAMENTO NACIONAL DE INFRAESTRUTURA DE TRANSPORTES. NORMA DNIT 010/2004 - PRO: Inspeções em pontes e viadutos de concreto armado e protendido - Procedimento. 2.ed. Rio de Janeiro, 2004.

. Publicação IPR - 709: Manual de Inspeção de Pontes Rodoviárias. 2.ed. Rio de Janeiro, 2004.

. Publicação IPR - 743: Manual de Sinalização Rodoviária. 3.ed. Rio de Janeiro, 2010.

. Sistema de gerenciamento de obras de arte especiais - SGO. Informativo do Núcleo de Comunicação Institucional da Diretoria de Planejamento e Pesquisa do DNIT. Disponível em: $<$ http://www.dnit.gov.br/download/SGO.pdf>. Acesso em: 19 dez. 2019.

. Sistema de gerenciamento de obras de arte especiais - SGO. Inspeção rotineira e dados cadastrais.

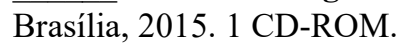

Instalação de Pingadeira com Guindaste em Osasco - SP - região de Cotia. Disponível em: $<$ https://cunzolo.com.br/guindastes-plataformas/produto/cotia/instalacao-pingadeira.htm>. Acesso em: 22 Dez. 2019. 